\title{
Author Spotlight: Gianmarco Farné
}

\section{Gianmarco Farné ${ }^{1}$}

Accepted: 19 May 2021 / Published online: 4 August 2021

(c) The Author(s), under exclusive licence to Springer Science+Business Media, LLC, part of Springer Nature 2021

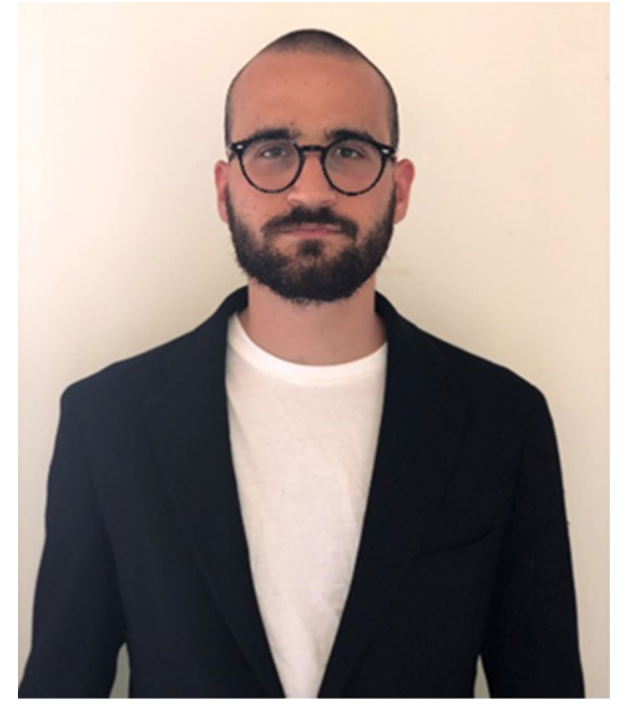

Gianmarco Farné (gianmarco.farne@ @studio.unibo.it) is currently a sixth-year student at the Medical School of the University of Bologna (UniBo)-Italy. He will graduate in October 2021. He is interested in general and emergency surgery.

Publisher's Note Springer Nature remains neutral with regard to jurisdictional claims in published maps and institutional affiliations.

Gianmarco Farné

gianmarco.farne@studio.unibo.it

1 Medical School, University of Bologna (UniBo), Bologna, Italy 